\title{
Change of Blood Sugar and Plasma Insulin Levels of Fishes in Glucose Tolerance Test*1
}

\author{
Masayuki FURUICHI and Yasuo YONE*2 \\ (Received January 26, 1981)
}

\begin{abstract}
In order to compare the ability to utilize carbohydrate of carp Cyprinus carpio, red sea bream Chrysophrys major, and yellowtail Seriola quinqueradiata (which were reared on the diets with $0 \%$, $10 \%$, and $40 \%$ dextrin for 30 days), they were subjected to a glucose tolerance test. The fishes showed a higher response of blood sugar and a lower response of insulin after the glucose administration than the responses of normal human beings. The glucose tolerance of yellowtail was lowest, followed by red sea bream, and carp in increasing order. The fishes exhibited a similar pattern of change in plasma insulin levels after the administration of glucose. However, the maximum level of plasma insulin and a ratio of the maximum plasma insulin level to the maximum blood sugar level (Max. IRI/Max. BS) was lowest in yellowtail, followed by red sea bream and carp in increasing order. Furthermore, in all species, the $40 \%$ dextrin diet groups showed a higher response of blood sugar, a lower response of insulin, and a lower value of Max. IRI/Max. BS than those of the $0 \%$ and $10 \%$ groups.
\end{abstract}

In the previous paper ${ }^{1)}$, the optimum level of dietary dextrin for maximum growth and feed efficiency was highest in carp, followed by red sea bream and yellowtail in decreasing order, and these species showed comparably high percent absorption of dextrin regardless of dietary dextrin levels. In another experiment with red sea bream ${ }^{2}$, it was found that the elevation of blood sugar level following glucose administration was depressed by the injection of insulin. From these results, authors supposed that the difference in the optimum level of dietary dextrin noticed between the fish species may be attributable to the difference in the carbohydrate utilizability resulting from the difference in the secretion of insulin after feeding. To confirm this presumption, the change in blood sugar and plasma insulin levels of.fishes which were subjected to the glucose tolerance test was examined in the present paper.

\section{Materials and Methods}

Fishes, Diets, and Feeding

The test fishes were carp, an omnivorous fish, red sea bream, a semi-carnivorous one, and yel- lowtail, an extremely carnivorous one, which were reared on the diets with and without dextrin in the previous study'). The selection and grouping of fish, preparation of diet, fish care, and feeding were carried out as described previously ${ }^{1)}$.

\section{Glucose Tolerance Test}

After a 30-day feeding trial, in which the fish were fed diets containing $0 \% 10 \%$, and $40 \%$ dextrin, they were starved for 18 hours and then subjected to the glucose tolerance test. Glucose enclosed in a gelatin capsule was orally administered at a level of $167 \mathrm{mg}$ per $100 \mathrm{~g}$ body weight which corresponds to $100 \mathrm{~g}$ glucose per $60 \mathrm{~kg}$ body weight in human being. Four to five fish from each group were sampled at random before and at 1-, 2-, 3-, and 5-hour periods after the administration of glucose, and blood was taken from the Cuvierian duct.

\section{Analytical Methods}

Blood sugar content was determined by the method of Momose et $a l^{3)}$. The plasma insulin level was quantified by the radioimmunoassay method which was presented in the previous paper $^{4)}$.

*1 Contribution from Fish. Res. Lab., Kyushu Univ., No. 148. The Utilization of Carbohydrate by Fishes-III. This work was supported in part by Grant-in-Aid for Encouragement of Young Scientist (Grant No. 176129) from the Ministry of Education, Science and Culture of Japan.

*2 Fish. Res. Lab., Kyushu Univ., Tsuyazaki. Fukuoka 811-33, Japan（古古政幸・米 廉夫：九州大学皆 学部附属水産実䅋所). 


\section{Results and Discussion}

Change of Blood Sugar Levels during Glucose Tolerance Test

As shown in Fig. 1, the blood sugar levels of carp and red sea bream were approximately $40 \mathrm{mg} /$ $100 \mathrm{ml}$ in the fasting state. The blood sugar level of carp reached maximum (approximately $180 \mathrm{mg}$ / $100 \mathrm{ml}$ ) at the 1-hour period after the administration of glucose and then returned nearly to the fasting level at the 5-hour period. However, the blood sugar level of red sea bream which elevated to maximum (approximately $180 \mathrm{mg} / 100 \mathrm{ml}$ ) at the 2-hour period did not decreased to the fasting level at the 5-hour period. On the other hand, yellowtail showed greater hyperglycemia than carp and red sea bream. Namely, the blood sugar level of yellowtail was approximately $120 \mathrm{mg} / 100 \mathrm{~m} l$ in the fasting state and elevated to maximum (approximately $210 \mathrm{mg} / 100 \mathrm{ml}$ ) at the 3-hour period after glucose administration, and was maintained at approximately $180 \mathrm{mg} / 100 \mathrm{~m} l$ even at the 5 -hour period.

In a normal human being, the blood sugar level which was estimated by the method of SomogyINeLSON $^{5)}$ is usually lower than $100 \mathrm{mg} / 100 \mathrm{~m} l$ in the fasting state and reaches maximum, which is lower than $140 \mathrm{mg} / 100 \mathrm{ml}$, at the 1 -hour period after the oral administration of $100 \mathrm{~g}$ glucose, and then decreases to less than $110 \mathrm{mg} / 100 \mathrm{ml}$ at the 2 -hour period. In a diabetic subject which has a low glucose tolerance, however, the blood sugar level shows values higher than $160 \mathrm{mg}$ and $150 \mathrm{mg} / 100 \mathrm{ml}$ at the 1- and 2-hour periods after administration $^{6)}$. Moreover, the high level of blood sugar is maintained for a long time.

In the present study, the response of blood sugar to the glucose administration was highest in yellowtail, and the time at which the blood sugar elevated to the maximum level and decreased to the fasting level was delayed in order of yellowtail, red sea bream, and carp. Accordingly, it can be considered from these findings that the glucose tolerance in the fishes tested is lowest in yellowtail, followed by red sea bream and carp in increasing order.

Change of Plasma Insulin Levels during Glucose Tolerance Test

All species exhibited a similar pattern of change in plasma insulin levels after the administration of glucose as shown in Fig. 2. Namely, the plasma insulin levels which were similar values (approximately $20 \mu \mathrm{U} / \mathrm{ml}$ ) in the fasting state increased to the maximum at nearly the 2-hour period after glucose administration. When the maximum insulin level was compared between the fish fed diets containing dextrin at the same level, however,

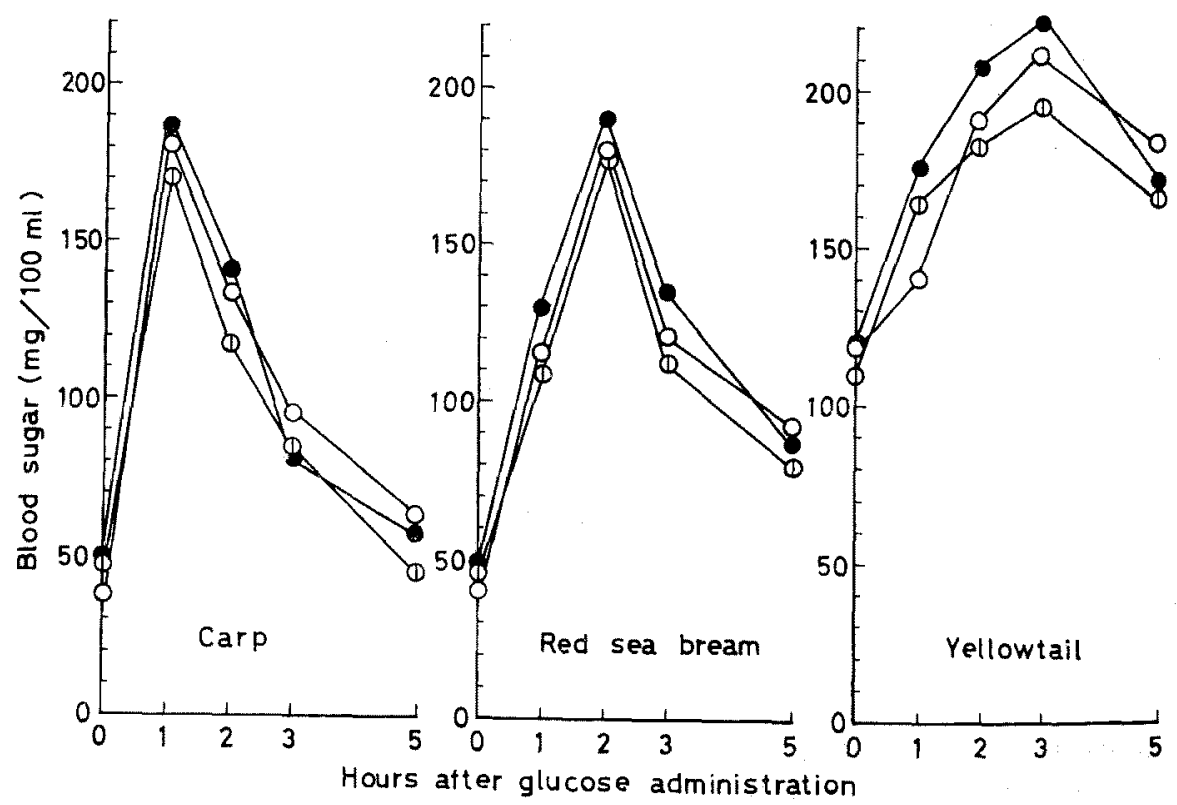

Fig. 1. Change in blood sugar levels of fishes, which were reared on diets with and without dextrin, after the oral administration of glucose at a level of $167 \mathrm{mg}$ per $100 \mathrm{~g}$ body weight.

, Dextrin-free diet group; (1. $10 \%$ dextrin diet group;, $40 \%$ dextrin diet group. 


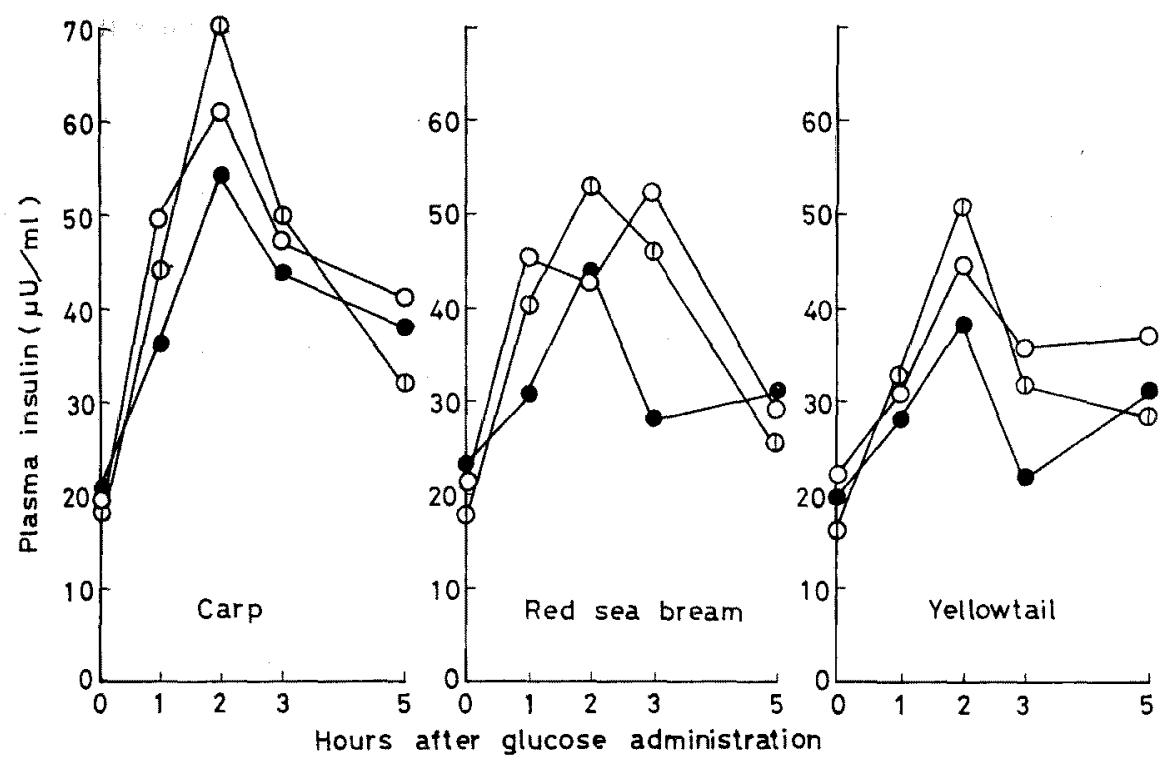

Fig. 2. Change in plasma insulin levels of fishes, which were reared on diets with and without dextrin, after the oral administration of glucose at a level of $167 \mathrm{mg}$ per $100 \mathrm{~g}$ body weight. $\bigcirc$, Dextrin-free diet group; $\mathcal{D}, 10 \%$ dextrin diet group;, $40 \%$ dextrin diet group.

it was highest in carp, followed by red sea bream and yellowtail in decreasing order (Table 1). It is of interest that the fish in which the optimum level of dietary dextrin for maximum growth and feed efficiency was lower ${ }^{13}$, showed a lower response of insulin and a higher response of blood sugar to the administration of glucose.

The plasma insulin level of a normal human being is 10 to $20 \mu \mathrm{U} / \mathrm{m} l$ in the fasting state similarly to that of fish, but it increases to the maximum (approximately 80 to $130 \mu \mathrm{U} / \mathrm{m} l$ ) at 30 - to 60 -minute period after the administration of $100 \mathrm{~g}$ glucose $^{7,8)}$. On the other hand, the maximum level of plasma insulin in a diabetic subject following glucose administration is lower than that of a normal human being, and the time to attain a maximum level of plasma insulin is later in the former than in the latter. In this experiment, the insulin response of fish to the administration of glucose was lower than that of a normal human being. Accordingly, it can be presumed from these results that the fishes tested are potential-diabetic by nature.

As described above, the maximum levels of blood sugar and plasma insulin after the administration of glucose are generally higher and lower, respectively, in the diabetic than in the non-diabetic subject. It is not appropriate, however, to evaluate the extent of the diabetic from the response of blood sugar or insulin, because individual varia- tions in these responses are considerable in both the diabetic and the non-diabetic subjects. Therefore, the ratio of the increment of plasma insulin level to the increment of blood sugar level at 30 -minute period after the administration of glucose (insulinogenic index: $\Delta \mathrm{IRI} / \Delta \mathrm{BS}$ ) is often used in order to discriminate the non-diabetic subject from the diabetic, and it has been reported that the insulinogenic index for the diabetic is lower than that for the non-diabetic subject ${ }^{8-18)}$. On the other hand, in case of fish, yellowtail indicated a high $\Delta$ IRI/ $\triangle B S$ value, because the fasting level of blood sugar in yellowtail was very high as compared with those of other species as shown in Fig. 1. Therefore, the $\Delta \mathrm{IRI} / \triangle \mathrm{BS}$ value was not adequate in order to compare the extent of potential-diabetic between the fish species. Accordingly, in the present study, a ratio of the maximum plasma insulin level to the maximum blood sugar level (Max. IRI/Max. BS) was calculated from the data of Fig. 1 and 2. As shown in Table 1, the Max. IRI/Max. BS value for carp which exhibited the highest optimum level of dietary dextrin was highest, followed by that for red sea bream and for yellowtail, which exhibited the lower optimum level of dietary dextrin, in decreasing order.

In the present study, the fish in which the optimum level of dietary dextrin for the maximum growth and feed efficiency is lower than that in domestic animals, manifested a higher response of 
Table 1. Ratio of maximum plasma insulin level to maximum blood sugar level (Max. IRI/Max, BS) of carp, red sea bream, and yellowtail

\begin{tabular}{|c|c|c|c|c|c|c|c|c|c|}
\hline \multirow{2}{*}{$\frac{\text { Fish }}{\text { Dextrain level in diet }(\%)}$} & \multicolumn{3}{|c|}{ Carp } & \multicolumn{3}{|c|}{ Red sea bream } & \multicolumn{3}{|c|}{ Yellowtail } \\
\hline & 0 & 10 & 40 & 0 & 10 & 40 & 0 & 10 & 40 \\
\hline $\begin{array}{l}\text { Max. blood sugar } \\
\quad(\mathrm{mg} / 100 \mathrm{~m} l)\end{array}$ & 181 & 170 & 187 & 180 & 176 & 191 & 212 & $19 \overline{5}$ & 223 \\
\hline $\begin{array}{l}\text { Max. plasma insulin } \\
(\mu \mathrm{U} / \mathrm{m} l)\end{array}$ & 61.0 & 70.2 & 54.1 & 52.6 & 53.0 & 43.8 & 44.5 & 51.3 & 38.2 \\
\hline Max. IRI/Max. BS & 0.34 & 0.41 & 0.29 & 0.29 & 0.30 & 0.23 & 0.21 & 0.26 & 0.17 \\
\hline
\end{tabular}

blood sugar and a lower response of plasma insulin than normal human beings to the administration of glucose. And also, the fish in which the optimum level of dietary dextrin is lower than other species, exhibited a higher response of blood sugar, a lower response of plasma insulin, and a lower value of Max. IRI/ Max. BS than other species. From these findings, it can be presumed that the fishes studied are potential-diabetic by nature, and that the difference in the optimum level of dietary dextrin noticed between the fish species can be attributed to the difference in the carbohydrate utilizability which resulted from the difference in the secretion of insulin by these species.

Furthermore, in all species, the fish group reared on the $40 \%$ dextrin diet which manifested poor growth and feed efficiency ${ }^{1)}$, showed a higher response of blood sugar, a lower response of plasma insulin and a lower value of Max. IRI/Max. BS as compared with those of corresponding $0 \%$ and $10 \%$ dextrin diet group. These results suggest that the carbohydrate utilizability of the fish may be reduced by long term feeding of high carbohydrate diets.

\section{Acknowledgments}

We are grateful to Mr. Y. KoHga of Shimizu Seiyaku Co., Ltd. for kindly supplying skipjack insulin, and to Dr. Y. Nakamura of Fukuoka Red Cross Hospital for kind suggestion in this work.

\section{References}

1) M. Furuichi and Y. YONE: Bull. Japan. Soc. Sci. Fish, 46, 225-229 (1980).

2) M. Furuichi and Y. YONE: Rep. Fish. Res. Lab., Kyushu Univ., No. 1, 101-106 (1971).

3) T. Momose, Y. Yano, and K. Ohashr: Chem. Pharm. Bull, 11, 968-972 (1963).

4) M. Furuichi, Y. Nakamura, and Y. YoNe: Bull. Japan. Soc. Sci. Fish., 46, 1177-1181 (1980).

5) M. Somogyi: J. Biol. Chem., 195, 19-23 (1952).

6) N. KuzuYa： J. Japan Diab. Soc., 13, 1-7 (1970).

7) I. KanaI and M. KanaI: Rinsho Kensa-ho Teiyo, 27th ed., Kinbara-shuppan, Tokyo, 1975, pp. XV. 36-37.

8) S. Nakagawa: Japan. J. Clin. Med., 34, 22812289 (1976).

9) H. S. Seltzer, E. W. Allen, A. L. Herron, JR., and M. T. BRENNAN: J. Clin. Invest., 46, 323-335 (1967).

10) K. KosaKa: J. Japan Med. Assoc., 66, 705-719 (1971).

11) R. Hagura, N. Kuzuya, and K. Kosaka: J. Japan Diab. Soc, 15 (Suppl.), 51 (1972).

12) R. Hagura: J. Japan Diab. Soc., 16, 455-459 (1973).

13) T. Toyota: J. Japan Diab. Soc., 16, 459-464 (1973).

14) T. IdE, H. Kazinuma, and H. SANDO: J. Japan Diab. Soc., 16, 470-474 (1973).

15) K. Kosaka, R. Hagura, T. Kuzuya, and N. KuZUYA: Diabetologia, 10, 775-782 (1974).

16) K. Kosaka, R. Hagura, and T. Kuzuya: Diabetes, 26, $944-952$ (1977).

17) K. Kosaka: J. Japan. Soc. Internal Med., 66, 1343-1361 (1977).

18) A. Sasaki, K. Matsumiya, M. arao, K. HaseGAWA, and N. HorIUCHI: J. Japan Diab. Soc., 21, 983-992 (1978). 